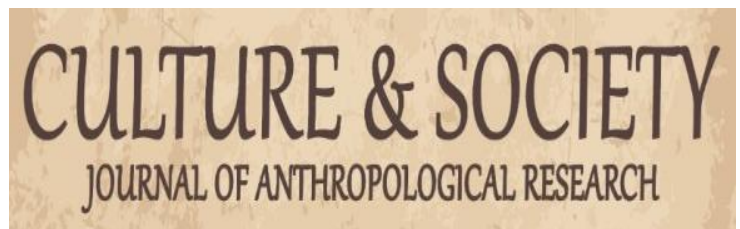

Culture \& Society: Journal of Anthropological Research

VOL. 1 NO. 1 SEPTEMBER 2019

http://culture.ppj.unp.ac.id

Email: culture@ppj.unp.ac.id

ISSN: 2686-343X (E-ISSN) 2686-3421 (P-ISSN)

DOI: https://doi.org/10.24036/culture/vol1-iss1/12

\title{
Dinamika Sosial dan Ekonomi Pekerja Tambang Emas Pasca Ditutupnya Tambang Emas Ilegal di Nagari Palangki Kabupaten Sijunjung
}

Indah Triyana Norisa ${ }^{1}$, Ikhwan Ikhwan ${ }^{2}$

\author{
${ }^{1,2}$ Universitas Negeri Padang;
}

Email:triyanaindah7@gmail.com, ichone.in@gmail.com

\begin{abstract}
Abstrak
Penelitian ini membahas dinamika sosial ekonomi pekerja tambang emas pasca ditutupnya tambang emas illegal di Nagari Palangki Kabupaten Sijunjung. Penelitian ini dianalisis menggunakan teori perukaran yang dikemukakan oleh George C Hooman. Penelitian ini dilakukan dengan pendekatan kualitatif dengann tipe penelitian studi kasus intrinsik. Pemilihan informan dilakukan secara purposive sampling dengann jumlah informan 11 orang. Pengumpulan data dilakukan dengann cara observasi non partisipasi, wawancara mendalam, dokumentasi.Hasil penelitian dari dinamika sosial ekonomi pekerja tambang emas pasca ditutupnya tambang emas ilegal di Nagari palangki, (1) Antara pekerja tambang dengan pemodal memiliki hubungan yang erat dan saling membutuhkan satu sama lain. Hubungan yang terjalin dalam bertransaksi diikat dengan nilai kerja sama sehingga membuat keduanya memiliki sikap saling percaya, tanggung jawab, tenggang serta mengutamakan sikap kekeluargaan. (2) Pekerja tambang dan pemilik modal sama sama memiliki keuntungan tertentu.
\end{abstract}

Kata Kunci : Dinamika Sosial, Pekerja Tambang emas, Pertukaran sosial

\section{Abstract}

This study discusses the socio-economic dynamics of gold mine workers after the closure of illegal gold mines in Nagari Palangki, Sijunjung Regency. This study was analyzed using the exchange theory proposed by George $C$. Hooman. This research was conducted with a qualitative approach with an intrinsic type of case study research. The selection of informants was done by purposive sampling with the number of informants 11 people. Data collection was carried out by means of non-participation observation, in-depth interviews, documentation. The results of research on the socio-economic dynamics of gold mine workers after the closure of illegal gold mines in Nagari palangki, (1) Between mine workers and financiers have a close relationship and need each other. Relationships that are established in a transaction are bound by the value of cooperation so as to make both of them have an attitude of mutual trust, responsibility, grace and give priority to family attitudes. (2) Mining workers and capital owners alike have certain advantages.

Keywords: Social Dynamics, Gold Mining Workers, Social Exchange

Received: August 29, 2019 Revised: September 4, 2019 Published: September 5, 2019

Culture \& Society: Journal of Anthropological Research Vol. 1, No. 1, Th. 2019 
Sumber daya alam adalah segala sesuatu yang muncul secara alami yang dapat digunakan untuk pemenuhan kebutuhan manusia pada umumnya (Fauzi, 2004). Sebagian daerah di indonesia juga dikenal penghasil berbagai jenis bahan tambang yaitu timah, gas alam, tembaga, batu bara, emas dan perak. Oleh karena itu harus dimanfaatkan sebaik-baiknya untuk kepentingan rakyat dengan memperhatikan kelestarian hidup sekitar. Menurut laporan Dinas Pertambangan dan Energi provinsi sumbar Tahun 2004, emas terdapat pada daerah Kabupaten Sijunjung, Lima Puluh Koto, Pasaman, Solok Selatan, dan Pesisir Selatan. Pada daerah Kabupaten Sijunjung, deposit emas diperkirakan terdapat disejumlah lokasi yang melalukan kegiatan pertambangan, seperti: Bukit Kebun, Batu Manjulur, Silokek, Palangki, Mundam Sakti, Muaro sijunjung, Lubuk Karia, Tanjung Ampalu, dan Jorong Koto Panjang (Sari \& Ardi Abas, 2013).

Nagari Palangki merupakan salah satu bagian dari wilayah Kabupaten Sijunjung yang melakukan kegiatan pertambangan emas, tambang emas yang berada di Nagari Palangki memiliki potensi ekonomi yang akan berdampak terhadap kehidupan ekonomi masyarakat. Dalam memanfaatkan sumber daya alam masyarakat bisa memperbaiki kehidupannya. penambangan emas ini dilakukan di area persawahan dan perbukitan sekitar pemukiman warga, sehingga lahan pertanian berubah menjadi lahan pertambang, karena menambang emas lebih menguntungkan dari pada bertani, penambang emas tidak lagi menjadi pekerjaan sampingan masyarakat, tetapi sudah dijadikan usaha dengan membutuhkan modal yang relatif besar. Sehingga mempengaruhi mata pencharian masyarakat dari petani ke penambang emas. Dengan banyaknya pencarian emas dan penjualan emas akan berdampak terhadap kehidupan ekonomi masyarakat kearah yang lebih baik akan tetapi tanpa disadari dengan naiknya ekonomi pekerja tambang akan mengakibatkan perubahan sosial terhadap orang orang sekitranya(Sarah, 2015).

penambangan emas yang menggunakan alat modern (escavator, dompeng, box). Aspek sosial yang terjadi antar masyarakat meningkat, bagaimana masyarakat bisa berbagi untuk bersama menujukkan tingkat solidaritas tinggi. Aspek ekonomi yang terjadi kebutuhan ekonomi tercukupi, pendapatan yang semakin meningkat ditandai dengan berubahnya gaya hidup yang menimbulkan pola hidup konsumtif, hal ini dibuktikan dari kemampuan masyarakat membeli motor, mobil, merenovasi rumah, serta memiliki kemampuan melanjutkan pendidikan anak-anaknya ke perguruan tinggi. Pernyataan tersebut akan berdampak kepada keinginan untuk meningkatkan taraf hidup baru, perbandingan pendapatan bertani dengan menambang(Arifin, 2015).

Operasi penambangan emas di Nagari Palangki ini tidak memiliki izin resmi sehingga dikenal dengan pertambangan tanpa izin (PETI). Tambang ini merupakan tambang emas ilegal (PETI) karena tidak sesuai dengan ketentuan perundangan tambang Nomor 24 Tahun 2009. Dalam undang-undang ini disebutkan bahwa untuk mendapatkan Izin Usaha Pertambangan (IUP) dan Izin Pertambangan Khusus (IPK), salah satu persyaratannya adalah harus sudah melakukan Analisis Mengenai Dampak Lingkungan (AMDAL) (Lestari, 2014). Terbukti dari adanya penambangan emas ilegal di Nagari Palangki berdampak pada kerusakan lahan,para pekerja juga mengesampingkan aspek keselamatan, pada saat penggalian emas dilakukan sudah banyak sekali korban yang terjebak di dalam lubang galian emas dan penambangan emas mengalami kemunduran karena cadangan emas sudah susah untuk ditemukan/ sudah habis. Tetapi ada beberapa penambang yang bertahan dengan ditutupnya tambang emas dengan cara, adanya kerja sama yang dilakuakn kelompok internal dan eksternal,, adanya membentuk kelompok, adanyak kontrak politik(Putri \& Putra, 2019).

Penelitian mengenai tentang tambang sudah banyak dilakukan oleh peneliti. Penelitian sebelumnya tentang tambang emas telah dilakukan oleh Trisnia Anjami dengan judul Dampak Sosial Penambangan Emas Tanpa Izin (PETI) di Desa Sungai Soriak Kuantan Hilir Seberang Kabupaten Kuantan Singingi. Hasil dari penelitian tersebut adalah adanya dampak positif dan dampak negatif dari penambangan emas tanpa izin (PETI). Dampak positifnya, membuka kesempatan kerja bagi masyarakat, meningkatkan pendapatan masyarakat yang bekerja sebagai buruh tambang (dompeng). Mengurangi angka pengangguran dan membantu membuka usaha

\section{Culture \& Society: Journal of Anthropological Research Vol. 1, No. 1, Th. 2019}


Indah Triyana, Ikhwan Ikhwan

Dinamika Sosial Dan Ekonomi Pekerja Tambang Emas

Pasca Ditutupnya Tambang Emas Ilegal Di Nagari Palangki Kabupaten Sijunjung

penunjang kegiatan pertambang seperti adanya warung makan dan usaha lainnya. Dampak negarifnya, kerusakan lingkungan, kerawanan sosial, perjudian, pemborosan sumber daya mineral, pencemaran terhadap air, dan juga bisa membuat orang bercerai (Trisnia Anjami, n.d.). Penelitian selanjutnya dilakukan oleh Merry Sartika dengan judul Konflik dalam Upaya Penertiban Tambang Emas Ilegal Studi Kasus Jorong Aur Jaya Nagari Koto Padang Kecematan Koto Baru Kabupaten Dharmasraya. Hasil dari penelitiannya adalah dari konflik tambang emas tersebut munculnya kekerasan dan adanya faktor-faktor penyebab terjadinya konflik sumber mata pencharian yang dilakukan secara ilegal (SARTIKA, 2015). Penelitian selanjutnya juga pernah dilakukan oleh EgaRani Safitri A yang berjudul Analisis Dampak Pertambangan Emas terhadap Kondisi Sosial Ekonomi Masyarakat Nagari Padang Sibusuk. Hasil dari penelitiannya adalah terdapat perubahan masyarakat setelah hadirnya pertambangan emas dimana terjadi peningkatan pendapatan masyarakat setelah bekerja di tambang emas dan tambang emas berdampak positif terhadap kondisi sosial masyarakat yaitu dari segi sarana pendidikan dan keterampilan masyarakat (Rani, 2018).

Sejalan dengan penelitian diatas, peneliti juga melakukan penelitian tentang dinamika yang terjadi pada aspek sosial dan ekonomi pasca ditutupnya tambang emas ilegal di Nagari Palangki Kabupaten Sijunjung. Penutupan tambang emas atau tidak beroperasinya tambang emas ilegal di Nagari Palangki mempengaruhi kepada kehidupan sosial dan ekonomi pekerja tambang emas tersebut. Ditutupnya tambang emas di Nagari Palangki Kabupaten Sijunjung membuat kehidupan masyarakat mengalami fluktuasi dalam aspek sosial dan ekonomi, karena tidak ada nya pekerjaan (pengangguran), setelah tambang emas tidak beroperasi. Sesuai dengan uraian dari latar belakang, maka dapat dirumuskan pertanyaan penelitian yaitu bagaimana dinamika sosial dan ekonomi pekerja tambang emas pasca ditutupnya tambang emas ilegal di Nagari Palangki Kabupaten Sijunjung. Sesuai dengan permasalahan diatas, maka tujuan dari penelitian ini adalah untuk mengetahui dinamika masyarakat pekerja tambang dilihat dari aspek kehidupan sosial dan ekonomi.

\section{Metode Penelitian}

Penelitian ini dilakukan Penelitian di Nagari Palangki Kabupaten Sijunjung. Pendekatan dalam penelitianPenelitian ini merujuk pada pendekatan kualitatif. Penelitian kualitatif bermaksud untuk menghasilkan data deskriptif berupa kata-kata tertulis atau lisan dari orangorang, dan perilaku yang diamati (Lexy, 2005). Tipe penelitian yang digunakan adalah studi kasus intrinsik, karena peneliti ingin mendapatkan pemahaman yang lebih mendalam dan komprehensif megenai dinamika sosial dan ekonomi pekerja tambang emas pasca ditutupnya tambang emas ilegal di Nagari Palangki Kabupaten Sijunjung. Melalui pendekatan ini data yang diperoleh lebih akurat dan peneliti juga bisa memperoleh data sebanyak mungkin melalui pertanyaan-pertanyaan yang di ajukan.Pemilihan informan dalam penelitian ini dilakukan secara purposive sampling. Informan penelitian adalah orang yang dapat memberikan informasi tentang situasi dan kondisi mengenai apa yang akan diteliti (Salim, 2001). Pemilihan informan penelitian ditentukan berdasarkan kriteria sebagai berikut: Pekerja tambang, pemilik modal/ Lahan , unsur pemerintah nagari, elit tradisional (niniak mamak, alim ulama dan cadiak pandai). Setelah melakukan penelitian informan berjumlah 11 orang yaitu, Elit adat 1 orang, pemilik modal 5 orang, pekerja tambang 4 orang, Wali Nagari 1 orang. Metode pengumpulan data dalam penelitian ini adalah observasi non partisipasiWawancara yang dilakukan yaitu wawancara mendalam (in-depth interview)(Bungin, 2003), dan studi dokumentasi. Triangulasi adalah cara yang paling umum digunakan dalam penjaminan validitas data dalam penelitian kualitatif. Triangulasi data merupakan salah satu teknik dalam pengumpulan data untuk mendapatkan temuan dan interpretasi data yang lebih akurat dan kridibel (A, 2014).analisis data adalah mengelompokkan data berdasarkan variable dan jenis responden, mentabulasi data berdasarkan variable dari seluruh responden, menyajikan data tiap variable yang diteliti, melakukan perhitungan untuk menjawab

Culture \& Society: Journal of Anthropological Research Vol. 1, No. 1, Th. 2019

2686-343X (E-ISSN) 2686-3421 (P-ISSN) 
Indah Triyana, Ikhwan Ikhwan

Dinamika Sosial Dan Ekonomi Pekerja Tambang Emas

Pasca Ditutupnya Tambang Emas Ilegal Di Nagari Palangki Kabupaten Sijunjung

rumusan masalah, dan melakukan perhitungan untuk menguji hipotesis yang telah diajukan (Sugiyono, 2017). Dalam penelitian proses analisis ini dilakukan melalui 4 tahap, berikut ini pengumpulan data, reduksi data, penyajian data, dan penarikan kesimpulan.

\section{Hasil dan Pembahasan}

\section{Kepemilikan Modal}

\section{Tambang Dibuka}

Kepemilikan modal adalah hal yang paling penting dalam melakukan pertambangan emas. Modal adalah hal yang paling utama untuk melakukan pertambangan karena pekerja tambang membutuhkan pemilik modal yang besar untuk melakukan penambangan emas. Modal itu termasuk uang, dan lahan. Apabila memilik lahan tapi tidak mempunyai uang sama saja tidak bisa membuka area pertambangan, untuk membuka area pertambangan tidak hanya lahan melainkan perlengkapan operasional lainnya. Jika si pemilik lahan tidak memiliki modal maka pemilik lahan menyewakan kepada si pemilik modal yang ingin bekerjasama atau menambang di lahannya. Pemilik modal dan pemilik lahan memiliki peranan yang amat penting. Kesepakatan dari pemilik modal dan lahan bisa menjadikan pemilik lahan mempunyai uang saku dan bisa dijadikan tabungan. Pemilik lahan membuat kesepakatan dengan pemilik modal dengan cara berkerja sama membagi hasil. pemilik modal mendapatkan keuntungan yang sangat besar, pemilik modal bisa menyewa titik emas yang ditentukan kepada pemilik lahan untuk melakukan penambangan emas, pembagian hasil dari tambang emas bisa dengan persenan yaitu $40 \%$ untuk modal, pekerja tambang $40 \%$, dan pemilik lahan 20\%. Dalam hal ini kehidupan sosial ekonomi pemilik modal menjadi meningkat dikarenakan berhasil mengelola pertambangan untuk mendapatkan keuntungan yang besar. Mereka dapat merubah kehidupannya yang hanya biasanya dengan lahan tersebut hanya bisa bercocok bertani dengan keuntungan sedikit, sekarang mendapatkan keuntungan yang besar. Para pemilik modal bisa memberikan sumbangan yang lebih, dan bisa membantu masyarakat sekitarnya. Dengan berubahanya pendapatan ekonomi akan berdampak kepada perubahan kehidpan sosial masyarakat penambang.

\section{Tambang Ditutup}

Berbeda hal dengan penutupan atau tidak beroperasinya tambang emas di Nagari Palangki, kegiatan penambangan emas di Nagari palangki dilakukan secara terus menerus sehingga membuat potensi emas berkurang dan lokasi lahan tambang sudah tidak ada. Hal lain yang terjadi yaitu karena penambangan emas rakyat yang tidak memiliki izin dari pihak terkait oleh sebab itu perizinan tidak ada dan menyebabkan tambang emas tersebut ditutup. Hal lain mempengaruhi kepada sosial dan ekonomi masyarakat. tambang emas ditutup karena hasil emas tidak begitu banyak lagi dan peetambang tidak di izinkan, menyebabkan pekerja tambang berhenti untuk mencari tambang emas. Dan pekerja tambang emas tidak memeiliki pekerjaan dan berdampak kepada pemilik modal untuk menutup tambang emasnya. Oleh karena itu pemilik modal yang memeiliki uang simpanan bisa mengembalikan lahan tambang menajdi lahan produktif, dan pemilik modal yang tidak memiliki uang akan membirkan tambang emas. mengatakan tambang emas di palangki itu sudah berkurang, andaikan adanya emas itu hanya sebanyak sa miang. Alhasil pemilik modal dan pekerja tambang yang biasanya mendapatkan keuntungan yang besar berakibat kepada pendapatan yang signifikan menurun. Bagi pekerja tambang yang tidak memiliki modal akan kembali bekerja untuk menjadi petani. Hal tersebut membuat kehidupan merekan berubah. akibat kandungan emas dan tidak adanya izin pertambangan emas mengakibatkan pemiliki modal gulung tikar dan tidak beroperasi tambang yang menyebakan pekerja tambang tidak memiliki pekerjaan. Alahsil pekerja tambang mencari pekerjaan lain yang biasanya mendapatkan upah yang besar sekarang hanya cukup untuk memenuhi kehidupan jauh dari kata mewah ketika masih banyaknya kandungan emas. Dinamika yang terjadi antara pemilik modal dan pekerja tambang

\section{Culture \& Society: Journal of Anthropological Research Vol. 1, No. 1, Th. 2019}


Indah Triyana, Ikhwan Ikhwan

Dinamika Sosial Dan Ekonomi Pekerja Tambang Emas

Pasca Ditutupnya Tambang Emas Ilegal Di Nagari Palangki Kabupaten Sijunjung

terlihat jelas bagaimana kehidupan pasca ditutupnya tambang emas illegal di Nagari Palangki Kabupaten Sijunjung.

\section{Menjadi Pekerja di Tambang Emas Ilegal}

Pekerja di tambang emas membawa dampak positif dan negatif bagi kehidupann masyarakat. Adanya tambang emas di Nagari Palangki meningkatkan perekonomian masayarakat karena adanya emas bisa menambah pendapatan masayarakat yang selama ini hanya bekerja di pertanian dan perkebunan,Kegiatan penambangan emas yang dilakukan di Nagari Palangki dilihat dari potensi emasnya sangat menjanjikan, sehingga masyarakat melakukan kegiatan penambangan secara besar-besaran, membuat perekonomian masyarakat meningkat. Akan tetapi sumber daya alam apabila di manfaatkan secara terus menerus akan habis dan berkurang, dan tidak adanya perizinan tambang mengakibatkan tambang emas menjadi ilegal dan ditutup. maka dari itu kegiatan penambangan emas yang berada di Nagari Palangki sudah tidak beroperasi. tidak adanya tambang emas mengubah kehidupan sosial ekonomi pekerja tambang. Hal tersebut dikarenakan tidak adanya lokasi untuk mencari emas. Pendapatan yang biasanya berjuta dalam seminggu sekarang kurang lebih ratusan ribu. Dahulu semenjak emas banyak para pekerja tambang bisa memenuhi kebutuhan hidup. Dahulunya bisa membantu sarana prasana lingkungan Nagari. Hal tersebut dapat mengangkat status sosial di masyarakat, yang biasanya dahulu susah untu memenuhi kebutuhan sekarang sudah bisa untuk memberikan bantuan kepada masyarakat. Hal lain juga terjadi ketika pendapatn pekerja tambang emas meningkat maka tingkat kebutuhan dan gaya hidup berubah. tidak berjalannnya atau ditutupnya tambang emas ini karena tidak adanya potensi emas itu sendiri, karena sumber daya alam tersebut diambil secara terus menerus untuk memenuhi kebutuhan hidup, hal ini mempengaruhi kepada kehidupan sosial ekonomi masyarakat karena tidak adanya tambang emas banyak masyarakat yang tidak bekerja, dan menjadi pengangguran malahan melakukan penyimpangan seperti berjudi.

Dinamika pekerja tambang emas terlihat ketika tambang emas masih aktif dan memiliki kandungan yang banyak para pekerja memiliki perekonomian yang membaik dan mengubah kehidupan sosial di tengah tengah masyarakat, biasanya tidak dipandang orang sekarang dihormati, para pekerja tambang juga merubah gaya hidup salah satu gaya hidupnya bisa membeli rumah, mobil, motor dan alat perabotan rumah tangga dan hal negatifnya melakukan penyimpangan sosial yaitu berjudi memakai narkoba dan mereka menghambur hamburkan uang karena dahulu uang mudah di dapat.

Setelah tambang emas ditutup pemilik modal mengalami kebangkrutan dan penutupan lahan, dan berdampak kepada pendapatan pemilik modal menurun mengakibatkan kehidupan mereka berubah dan berakibat kepada pekerja tambang yang menjadi kehilangan pekerjaan yang biasanya mempunyai pendapatn yang banyak sekarang tidak ada lagi. Hal tersebut berpengaruh kepada kehidupan pekerja tambang. Hal yang paling utama berubah yaitu pendapatan yang berkurang berakibat kepada penyimpangan sosial.

Teori pertukaran yang dikemukakan oleh George Casper Homans memiliki asumsi: Pertama, manusia adalah makhluk yang rasional, dia memperhitungkan untung dan rugi. Kedua, transaksi pertukaran terjadi hanya apabila pihak yang terlibat memperoleh keuntungan dari pertukaran itu (Ritzer, 2014).

Pekerja tambang dan pemilik modalmerupakan aktor yang beperan dalam melakukan pertukaran. Pemilik modal mendanai untuk mengelola pertambangan mengolah hasil produksi dan menjual hasil produksi, sedangkan pekerja tambangorang yang menambang di lokasi pemodal. Antara pekerja tambang dengan pemodal memiliki hubungan yang erat dan saling membutuhkan satu sama lain. Hubungan yang terjalin dalam bertransaksi diikat dengan nilai kerja sama sehingga membuat keduanya memiliki sikap saling percaya, tanggung jawab, tenggang serta mengutamakan sikap kekeluargaan.

Pekerja tambang dan pemilik modal sama sama memiliki keuntungan tertentu, pekerja tambang memiliki pendapatan yang lebih dari tambang emas. Pemilik modal membutuhkan

Culture \& Society: Journal of Anthropological Research Vol. 1, No. 1, Th. 2019

2686-343X (E-ISSN) 2686-3421 (P-ISSN) 
Indah Triyana, Ikhwan Ikhwan Dinamika Sosial Dan Ekonomi Pekerja Tambang Emas Pasca Ditutupnya Tambang Emas Ilegal Di Nagari Palangki Kabupaten Sijunjung

pekerja tambang untuk mengelola pertambangan dan menjual hasil produksi. Dan apabila pemilik modal mengalami kebangkrutan berpengaruh kepada pekerja tambang yang dapat kehilangan pekerjaan dan mengubah status sosial dan perubahan dalam kehidupannya.

\section{Kesimpulan}

Dinamika sosial dan ekonomi pekerja tambang emas pasca ditutupnya tambang emas illegal, pemilik modal dan pekerja tambang dalam hubungan saling ketergantungan dan saling membutuhkan. karena pemilik modal dan pekerja tambang pasca ditutupnya tambang emas illegal ini berdampak kepada aspek sosial ekonomi, yang mana ketika tambang dibuka pemilik modal dan pekerja tamabang memiliki hubungan yang kuat yang menimbulkan solidaritas yang tinggi, pendapatan perekonomian tinggi berakibat kepada sikap positif. Setelah tambang ditutup, pekerja tambang dam pemilik modal sangat berdampak kepada aspek sosial ekonomi, hubungan yang renggang, yang berdampak kepada sikap induvidualis, dan, meningkatan pengangguran yang bermuara kepada perilaku menyimpang.

\section{Daftar Pustaka}

A, M. Y. (2014). Metode Penelitian Kuantitaif, Kualitatif \& Penelitian Gabungan. Jakarta: Kencana. Arifin, D. S. (2015). .Dampak Peralihan Mata Pencarian terhdapa mobilitas sosial (studi pada masyarakat, lampoon dusun Ringisari desa pesanggaran Kecamatan, Pesanggaran, Kabupaten Bayuwangi.

Bungin, burhan. (2003). Analisis Data Penelitian Kualitatif. Jakarta: PT Raja Grafindo Persada.

Fauzi, A. (2004). Ekonomi Sumber daya Alam dan Lingkungan. Jakarta: Gramedia Pustaka Utama.

Lestari, E. (2014). Tambang Emas Di Lahan Sawah (studi Kasus: pilihan-pilihan masyarakat nagari padang sibusuk, kabupaten sijunjung, dalam pengalihanfungsian lahan pertanian menjadi tambang emas ilegal. Encyclopedia of Quality of Life and Well-Being Research, (1), 52435245. https://doi.org/10.1007/978-94-007-0753-5_2337

Lexy, J. M. (2005). Metodeologi penelitian kualitatif. Bandung: Remaja Rosdakarya.

Putri, J., \& Putra, E. V. (2019). Kebertahanan Tambang Emas Ilegal Di Jorong Durian Simpai Nagari Koto Nan Iv Di Bawuah Kecamatan Ix Koto Kabupaten Dharmasraya. Jurnal Perspektif, 2(1), 47-51. doi:10.24036/ppkt/vol2-iss1/64

Rani, E. S. (2018). Analisis Dampak Pertambangan Emas Terhadap Kondisi Sosial Ekonomi Masyarakat Nagari Padang Sibusuk Tahun 2017. (1), 430-439.

Ritzer, G. (2014). Teori Sosiologi Modern. Jakarta: Kencana.

Salim, A. (2001). Teori dan Paradigma Penelitian Sosial. Yogyakarta: PT Tiara Wacana.

Sarah, S. N. (2015). Dinamika Sosial Ekonomi Pekerja Tambang Emas Tradisional Di Desa Ciwaru Kecamatan Ciemas Kabupaten Sukabumi Universitas Pendidikan Indonesia | repository.upi.edu | perpustakaan.upi.edu.

Sari, M. A., \& Ardi Abas, D. (2013). Dari Petani Ke Penambang; Perubahan Sosial Ekonomi Di Jorong Koto Panjang, Nagari Limo Koto, Kabupaten Sijunjung. Jurnal Ilmu Sosial Mamangan, 2(1), 15-21. https://doi.org/10.22202/mamangan.1368

Sartika, M. (2015). Konflik Dalam Upaya Penertiban Tambang Emas Ilegal (Studi: Jorong Aur Jaya Nagari Koto Padang Kecamatan Koto Baru Kabupaten Dharmasraya).

Sugiyono. (2017). Metode Penelitian Kuantitatif, Kualitatif, dan R\&D. Bandung: Alfabeta.

Trisnia Anjami. (n.d.). Dampak Sosial Penambangan Emas tanpa Izin (PETI) di Desa Sungai Soriak Kecamatan Kuantan Hilir Seberang Kabupaten Kuantan Singingi. 5, 1-13. Retrieved from http://weekly.cnbnews.com/news/article.html?no=124000 